IP Periodica Polytechnica Civil Engineering

61(3), pp. 554-563, 2017

https://doi.org/10.3311/PPci.8183

Creative Commons Attribution (i)

RESEARCH ARTICLE

\section{Engineering Properties of Bentonite- Lime-Phosphogypsum Composite Reinforced with Treated Sisal Fibers}

\author{
Sujeet Kumar $^{1 *}$, Vidya Tilak B. ${ }^{2}$, Rakesh Kumar Dutta ${ }^{2}$
}

Received 28 April 2015; Revised 20 February 2016; Accepted 19 May 2016

\begin{abstract}
The present work primarily investigates the unconfined compressive strength, the tensile load-diametral strain, the toughness characteristics and the shear strengths of bentonite-limephosphogypsum-treated sisal fibre composite. The unconfined compressive strengths and tensile strengths were obtained using the unconfined compressive test and indirect tensile test respectively. The results revealed that the unconfined compressive stress, the deviator stress and the tensile load at failure of bentonite-lime-phosphogypsum composite with untreated sisal fibres could be improved by the successive chemical treatment with sodium periodate, p-aminophenol and sodium hydroxide. The brittleness index and deformability index indicated a change from the brittle to ductile behavior of the bentonitelime-phosphogypsum-untreated sisal fiber composite, with the chemical treatment.
\end{abstract}

\section{Keywords}

bentonite-lime-phosphogypsum, compressive strength, tensile strength, treated sisal fiber

\footnotetext{
${ }^{1}$ Department of Civil Engineering, Indian Institute of Technology (BHU), Varanasi - 221005, Uttar Pradesh, India,

${ }^{2}$ Department of Civil Engineering, National Institute of Technology, Hamirpur - 177005, Himachal Pradesh, India,

*Corresponding author email: sujeetkumar.ce@gmail.com
}

\section{Introduction}

Bentonite is an absorbent aluminium phyllosilicate clay consisting mostly of montmorillonite. It is formed by the weathering of volcanic ash. USA, Greece, Australia, India, Russia and Ukraine have bentonite spreads. These expansive soils pose serious problems to structures constructed over them in terms of differential settlements, poor strength and high compressibility especially during rainy season. Thus, it is treated with additives like lime and phosphogypsum and analysed in detail in our earlier study [1]. The bentonite-lime-phosphogypsum composite, however, posed low tensile strength. One of the possible efforts to improve the tensile strength was that of reinforcing the soil composite. Synthetic fibres, natural fibers, metallic elements and geo-synthetics are a few among them. Owing to the environmental damages, global warming and constant rise in the climate changes caused due to the synthetics manufacturing, the authors have considered to drive a study on natural fibres and their consequent application in construction industry. Natural fibres like banana, sisal, hemp and flax, jute, coconut, bamboo, sponges, wood dusts and oil palm [2] have attracted scientists. Sisal is one such plant fibre produced abundantly in eastern part of India and is used to make ropes and twine. Sisal fiber is fairly coarse and inflexible. It possesses moderately high specific strength and stiffness, durability, ability to stretch, and resistance to deterioration in saltwater [3]. The main disadvantages of natural fibers in composites have been the poor compatibility between fiber and matrix and the relative high moisture sorption. Therefore, chemical treatments are considered in modifying the fiber surface properties.

Various researchers [2-12] have studied the effect of different chemicals and reported improvement in the properties of sisal fibers. Sisal fibers inherently facilitate characteristic surface modification and the hollow helical microstructure of sisal fibers being responsible for the very distinctive failure mechanism reasons the choice of the fiber among many other available natural fiber [13]. The presence of waxy particles on the surface of sisal fibers leads to reduction in the mechanical properties [14]. This motivated the researchers [15-16] to experiment different surface modification techniques such as alkali treatment, 
dewaxing, vinyl grafting, etc. A significant reduction in the moisture absorption and improved wettability of Brazilian variety of sisal fibers was observed after surface treatment with $\mathrm{NaOH}$ or $\mathrm{N}$-isopropyl-acrylamide solutions [17]. It was further reported that surface alteration, improved thermal and mechanical resistance, improved interfacial adhesion, increased tensile strength of sisal fibers with the treatment. Investigator [18] studied the effect of $5 \% \mathrm{NaOH}$ on the sisal fibers and reported an increase of $21 \%$ in flexural strength. The effect of sisal fibers on the compaction and unconfined compressive strength of lime treated black cotton soil was further analysed and was reported that addition of sisal fibers to lime treated black cotton soil increased maximum dry unit weight and the unconfined compressive strength and changed the behaviour from brittle to ductile [19]. Researcher [20] studied the effect of random inclusion of sisal fibers on strength behaviour of lime treated black cotton soils and reported an increase in unconfined compressive strength of lime treated expansive soil with the addition of sisal fibers and with the curing period. A decrease in the unconfined compressive strength and increase in the optimum moisture content of bentonite-lime-phosphogypsum with the addition of sisal fibers was reported by [21]. From the literature presented above, it is evident that the engineering properties like compaction, unconfined compressive strength, strength parameters and tensile strength of bentonite-lime-phosphogypsum mix reinforced with sodium periodate, $\mathrm{p}$-aminophenol and sodium hydroxide treated sisal fibers has not been reported so far. The present study attempts to fill this gap.

\section{Materials Used and Experimental Procedure}

Commercially available bentonite of specific gravity (according to IS 2809:1972 [22] and IS 2720:1980-Part III-sec I [23]), liquid limit, plastic limit, dry unit weight and optimum moisture content of 2.30, $220 \%$ and $39.74 \%, 13.95 \mathrm{kN} / \mathrm{m}^{3}$ and $27.98 \%$ respectively was used. As per Universal Soil Classification System, the clay was classified as clay of high compressibility. Hydrated lime and phosphogypsum were brought from the retailers. The specific gravity of lime and phosphogypsum used was 2.37 and 2.20 respectively. The content of lime and phosphogypsum was varied from 0 to $10 \%$ and 0 to $10 \%$ respectively. The sisal fibers were brought from a local supplier in Bihar, India and were cut into $15 \mathrm{~mm}$ in length with scissors. The specific gravity, diameter and tensile strength of the sisal fibers used in this study were $1.40,0.25 \mathrm{~mm}$ and $405.2 \mathrm{~N} / \mathrm{mm}^{2}$ respectively. To remove the surface impurities (wax, natural oils, cellulose, lignin, hemicelluloses, lumen etc.) present on the surface of natural sisal fibers, these fibers were given a prewash with tap water followed by washing in distilled water. The washed sisal fibers were then dried. The chemicals used to treat the sisal fiber were sodium periodate, $\mathrm{p}$-aminophenol and sodium hydroxide and their chemical composition is shown in Table 1.
Table 1 Chemical composition and properties of the chemicals used

Chemical name

\begin{tabular}{|c|c|c|}
\hline p-Aminophenol & $\begin{array}{l}\text { Sodium Periodate } \\
\left(\mathrm{NaIO}_{4}\right)\end{array}$ & Sodium Hydroxide $(\mathrm{NaOH})$ \\
\hline & M.W. 213.89 & M.W. 40.00 \\
\hline M. W. 109.13 & Minimum assay - & Assay $-97 \% \min$ \\
\hline Minimum assay & $98.0 \%$ & Sulphate $\left(\mathrm{SO}_{4}\right)-0.05 \% \max$ \\
\hline $96.0 \%$ & Maximum limits of & Potassium $(K)-0.1 \% \max$ \\
\hline (Non-aqueous; & impurities: & Zinc $(Z n)-0.02 \% \max$ \\
\hline Potentiometric) & Bromate, bromide, & Lead $(P b)-0.001 \% \max$ \\
\hline Melting Point & chlorate and chlo- & Chloride $(C l)-0.01 \% \max$ \\
\hline about $184^{\circ} \mathrm{C}$ & ride $(C l)-0.01 \%$ & Carbonate $\left(\mathrm{Na}_{2} \mathrm{CO}_{3}\right)-2 \% \max$ \\
\hline (decom.) & Sulphate $\left(\mathrm{SO}_{4}\right)-$ & Silicates $\left(\mathrm{SiO}_{2}\right)-0.05 \% \max$ \\
\hline Sulphated ash & $0.005 \%$ & $10 \%$ Aqueous solution - clear \& \\
\hline \multirow[t]{2}{*}{ Max. $2.0 \%$} & Manganese $(M n)-$ & colourlesses \\
\hline & $0.0005 \%$ & $\operatorname{Iron}(F e)-0.001 \% \max$ \\
\hline
\end{tabular}

The dried sisal fibers were first oxidized with $20 \% \mathrm{w} / \mathrm{v}$ aqueous solution of $\mathrm{NaIO}_{4}$ to produce cellulose aldehyde. After the oxidation, sisal fibers were washed with tap water to remove the excess of $\mathrm{NaIO}_{4}$ (Designated as SFT1). This is designated as first stage of treatment. The first stage treated sisal fibers were then immersed in a solution of $5 \% \mathrm{p}$-aminophenol for about $4 \mathrm{~h}$ at $70{ }^{\circ} \mathrm{C}$ (Designated as $S F T 2$ ). This is designated as second stage of treatment. After the second stage of treatment, sisal fibers were taken out of the beaker and washed first with $1 \%$ solution of sodium hydroxide followed by distilled water (Designated as SFT3). This is designated as third stage of treatment. The treated sisal fibers (SFT1, SFT2, SFT3) were then dried in open air and finally in an oven at $85^{\circ} \mathrm{C}$. The dried sisal fibers were kept in a sealed container for further use. The standard proctor compaction tests [24] were conducted on bentonitelime and bentonite-lime- phosphogypsum and bentonite-lime phosphogypsum with and without treated sisal fibers and water was added as needed to facilitate the mixing and compaction process. The unconfined compressive strength, unconsolidated undrained triaxial and tensile strength tests [25-27] were subsequently conducted. For the preparation of specimens for these tests, required quantities of bentonite, lime, phosphogypsum and sisal fibers were mixed in dry state. The sisal fibers have a tendency to lump together. Therefore, a considerable care and time was spent to separate them to get an even distribution of the fibers in the mixture. The dry bentonite-lime-phosphogypsum-sisal fiber mixture was then mixed with the required amount of water corresponding to optimum moisture content. All the mixing was done manually and proper care was taken to prepare homogeneous mixtures at each stage of mixing. The mix was then placed inside the mould. To ensure uniform compaction, the specimen was compressed statically from both ends till the specimen just reached the dimensions of the mould. Then, the specimen was extracted with the hydraulic 
jack and was placed in an air tight polythene bags which were placed inside the desiccator for curing for 3, 7, 14 and 28 days. The specimen was taken out of the desiccator and polythene bag after the desired period of curing and tested for unconfined compressive strength, unconsolidated undrained triaxial and tensile strength. Failed specimens of unconfined compression tests were powdered and sieved through a $45 \mu \mathrm{m}$ sieve and gold-coated prior to scanning electron micrographs (SEM) tests. Energy Dispersive X-ray Analysis (EDAX) was simultaneously performed with $S E M$. For easy reference and identification of specimen, specific codification was used. Specimens containing only bentonite and lime (without sisal fiber) were designated by four letter codification. The first letter of codification indicates bentonite; the next three digits indicate percent lime. For example, code $B 08 L$ will indicate bentonite mixed with $8 \%$ lime. For specimens containing bentonite-lime-phosphogypsum (without sisal fiber) was designated by nine letter codification. The first letter of codification indicates bentonite, the next three digits and next to next five digits indicates the percent lime and percent phosphogypsum respectively. For example, code $B 08 L 005 P G$ will indicate bentonite mixed with $8 \%$ lime and $0.5 \%$ phosphogypsum. For specimens containing sisal fibers, a fifteen letter codification scheme was used. The first letter of codification indicates bentonite; the second three digits and third five digits indicate percent lime and phosphogypsum content respectively. The next four digits indicate the percent sisal fibers. The remaining two digits indicate the chemical treatment. For example, code B08L005PG05SFT1 will indicate bentonite mixed with $8 \%$ lime, $0.5 \%$ phosphogypsum, $0.5 \%$ sisal fibers and treated with $T 1$ process.

\section{Testing Results and Analyses}

\subsection{Optimum mix of bentonite-lime-phosphogypsum- sisal fibers}

In order to fix the reference mix for the bentonite-lime-phosphogypsum-sisal fiber, a multi-variable approach is used. For this, compaction, unconfined compressive strength and unconsolidated undrained triaxial tests were conducted. The results of compaction for the different proportions of bentonite-limephosphogypsum-sisal fiber mixture are shown in Table 2. Study of Table 2 reveals a decrease in the maximum dry unit weight and increase in the optimum moisture content of bentonite with the increase in the lime content. Decrease in the maximum dry unit weight is attributed to the quick reaction of lime with bentonite resulting Base Exchange aggregation and flocculation leading to increase in void ratio of the mixture resulting decrease in the dry unit weight of the mix. The increase in optimum moisture content with the addition of lime to the bentonite is due to additional water held within the flocs resulting from flocculation due to lime reaction. Further from Table 2, it is observed that the maximum dry unit weight and the optimum moisture content increases with the addition of phosphogypsum to the bentonite-lime mix. This increase in the dry unit weight and the optimum moisture content is attributed to the fact that the phosphogypsum fills up the void spaces left out after quick reaction of bentonite with lime resulting Base Exchange aggregation and flocculation. Similar observations were reported on lime-stabilized kaolinite in the presence of sulphates by [28]. A close examination of Table 2 further reveals that the decrease in the dry unit weight and increase in the optimum moisture content with the addition of sisal fiber to the bentonite-lime-phosphogypsum mix is observed. Decrease in dry unit weight and increase in optimum moisture content due to sisal fiber addition is attributed to lower specific gravity and water absorbing tendency of the sisal fibers respectively. Similar observations were observed where the effect of sisal fibers on the black cotton soil and lime treated black cotton soil was analysed by [29]. Thus, from the above discussion, it is observed that there is no clear trend as evident from Table 2 to fix the optimum content of sisal fibers. In order to decide the optimum mix of bentonitelime-phosphogypsum-sisal fibers composite, it was decided to conduct unconfined compressive strength tests. The results of the unconfined compressive strength of bentonite-lime-phosphogypsum-sisal fiber composite cured for 3, 7, 14 and 28 days respectively are shown in Table 3.

Table 2 Compaction characteristics of bentonite-lime-phosphogypsum with and without treated sisal fiber composite.

\begin{tabular}{lcc}
\hline Mixes & MDD $\left(\mathrm{kN} / \mathrm{m}^{3}\right)$ & OMC $(\%)$ \\
\hline B & 13.95 & 27.98 \\
B02L & 13.72 & 29.88 \\
B04L & 13.45 & 31.71 \\
B06L & 13.37 & 31.90 \\
B08L & 13.34 & 32.40 \\
B10L & 13.29 & 33.20 \\
B08L005PG & 13.25 & 32.98 \\
B08L010PG & 13.49 & 33.05 \\
B08L020PG & 13.59 & 33.38 \\
B08L040PG & 13.73 & 33.65 \\
B08L080PG & 13.89 & 33.89 \\
B08L100PG & 14.01 & 34.05 \\
B08L080PG05SF & 13.18 & 31.00 \\
B08L080PG10SF & 13.02 & 33.00 \\
B08L080PG15SF & 13.44 & 30.50 \\
B08L080PG20SF & 13.20 & 3.00 \\
B08L080PG10SFT1 & 13.25 \\
B08L080PG10SFT2 & 13.00 \\
B08L080PG10SFT3 & 13.50 \\
\hline
\end{tabular}


Table 3 Unconfined compressive strength of bentonite-lime-phosphogypsum-sisal fiber composite

\begin{tabular}{|c|c|c|c|c|}
\hline \multirow{3}{*}{ Mixes } & \multicolumn{4}{|c|}{ Unconfined compressive strength ( $\mathrm{kPa})$} \\
\hline & \multicolumn{4}{|c|}{ Curing period (days) } \\
\hline & 3 & 7 & 14 & 28 \\
\hline B & 154.25 & 154.26 & 158.89 & 162.03 \\
\hline B02L & 248.24 & 287.51 & 303.60 & 311.01 \\
\hline B04L & 325.25 & 345.93 & 347.04 & 371.29 \\
\hline B06L & 387.47 & 404.06 & 535.82 & 1057.87 \\
\hline B08L & 442.77 & 1378.89 & 1395.02 & 1446.11 \\
\hline B10L & 306.54 & 910.85 & 931.06 & 950.14 \\
\hline B08L005PG & 225.15 & 467.33 & 810.00 & 584.01 \\
\hline B08L010PG & 321.67 & 496.38 & 817.00 & 620.36 \\
\hline B08L020PG & 363.53 & 592.26 & 831.00 & 661.91 \\
\hline B08L040PG & 429.49 & 652.10 & 921.00 & 761.09 \\
\hline B08L080PG & 450.24 & 726.24 & 1122.30 & 843.20 \\
\hline B08L100PG & 357.65 & 473.00 & 635.67 & 531.52 \\
\hline B08L080PG05SF & 373.90 & 433.21 & 830.52 & 944.30 \\
\hline B08L080PG10SF & 515.47 & 584.12 & 898.63 & 1129.63 \\
\hline B08L080PG15SF & 335.90 & 580.27 & 606.54 & 703.11 \\
\hline B08L080PG20SF & 289.20 & 446.86 & 481.01 & 509.66 \\
\hline B08L080PG10SFT1 & 535.06 & 640.78 & 906.73 & 1138.49 \\
\hline B08L080PG10SFT2 & 795.53 & 843.99 & 934.12 & 1185.19 \\
\hline B08L080PG10SFT3 & 416.91 & 554.30 & 906.23 & 954.22 \\
\hline
\end{tabular}

Study of Table 3 reveals that at a curing period of 3 days, the unconfined compressive strength of the bentonite increased with the increase in lime content up to $8 \%$. Beyond a content of $8 \%$, the unconfined compressive strength decreased. Similar trend was observed for other curing periods of 7,14 and 28 days respectively. The increase in unconfined compressive strength with the curing period is attributed to the pozzolanic reactions of lime with the bentonite leading to increase in strength. The decrease in strength beyond a lime content of $8 \%$ is attributed to the platy shapes of the unreacted lime particles in bentonite. Therefore a mix B08L was chosen for studying the unconfined compressive strength by varying the content of phosphogypsum. Table 3 reveals that the increase in the unconfined compressive strength was up to a phosphogypsum content of $8 \%$ and a curing period of 14 days and beyond this the trend was reverse. The increase in compressive strength with the curing period is attributed to the acceleration in the pozzolanic reactions of lime with the bentonite in the presence of phosphogypsum leading to increase in unconfined compressive strength up to 14 days of curing. Beyond 14 days of curing, the formation of ettringite perhaps decreased the unconfined compressive strength. Therefore, a mix B08L080PG was chosen for studying the unconfined compressive strength by varying the content of sisal fibers. Table 3 further reveals that the unconfined compressive strength increased with the addition of sisal fibers up to a fiber content of $1 \%$. This is attributed to the fact that the cementing gel formed due to the reaction bentonite with lime, binds the sisal fibers with the bentonite particles leading to an enhancement in the unconfined compressive strength. The unconfined compressive strength decreased beyond a fiber content of $1 \%$. This may be due to formation of lump of fibers due to excessive adhesion and poor contact of fibers with bentonite particles resulting decrease in unconfined compressive strength. The above discussion reveals that the mix B08L080PG10SF is the optimum one.

In order to validate that the mix B08L080PG10SF was really the optimum mix, it was decided to conduct unconsolidated undrained triaxial tests. The results of the deviator stress obtained from the triaxial tests with varying percentage of lime, phosphogypsum, sisal fibers and chemically treated sisal fibers and cured for 28 days are shown in Fig. 1(a) to (d) respectively. The strength parameters are shown in Table 4. Study of Fig. 1(a) reveals that the deviator stress at failure increased with the increase in lime content up to a content of $8 \%$. Beyond a lime content of $8 \%$, the deviator stress decreased. The trend was consistent at other confining pressure also as evident from Fig. 1(a). The improvement in deviator stress at failure up to lime content of $8 \%$ is attributed to that formation of cementing compound due to pozzolanic reaction. The decrease in deviator stress beyond a lime content of $8 \%$ is attributed to decrease in cohesion of mix as evident from Table 4. Therefore, on the basis of the results of the compaction, unconfined compressive strength and triaxial tests, the mix $B 08 L$ was chosen for studying the variation in deviator stress at failure by varying the content of phosphogypsum. The results of the deviator stress at failure of the mix $B 08 L$ with varying percentage of phosphogypsum and at a confining pressure 50, 100 and 200 $\mathrm{kPa}$ respectively is shown in Fig. 1(b). This figure reveals that the deviator stress at failure increased up to a phosphogypsum content of $8 \%$ and the trend was reverse after this. Decrease in the deviator stress beyond $8 \%$ phosphogypsum perhaps is attributed to the possible effect of sulphates which reduce the formation of the pozzolanic compounds leading to a decrease in the cohesion of the mix as evident from Table 4. Figure 1(b) further reveals that the deviator stress of the mix $B 08 L 005 P G$ is less than that of $B 08 L$. This may be due to the effect of impurities and sulphates present in the phosphogypsum. Therefore, on the basis of the results shown in Figs. 1(a) and 1(b), a mix of $B 08 L 080 P G$ was chosen for studying the variation in deviator stress by varying the sisal fibers. The results are shown in Fig. 1(c). This figure reveals that the deviator pressures too. The increase in deviator stress at failure is due to the reinforcing action of the sisal fibers leading to increase in the deviator stress at failure. The decrease in deviator stress beyond a fiber content of $1 \%$ is attributed to the formation of lump of fibers 
due to poor contact with bentonite particles. Therefore, on the basis of the multi-variable approach stated in earlier section, a mix of B08L080PG10SF is conclusively the optimum mix which has been used for further study.

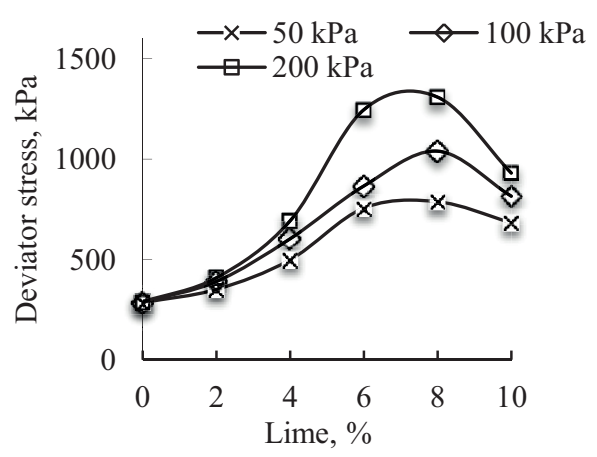

(a)

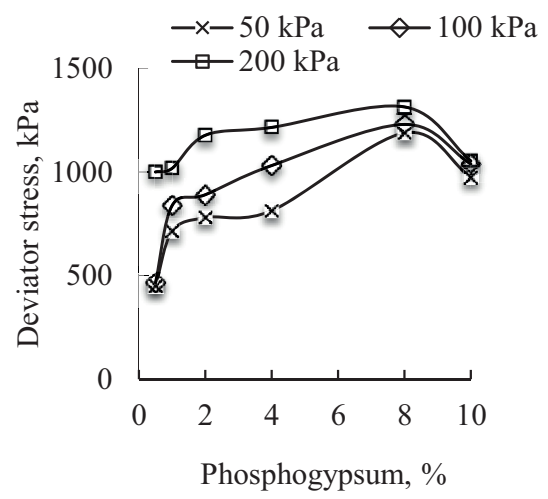

(b)

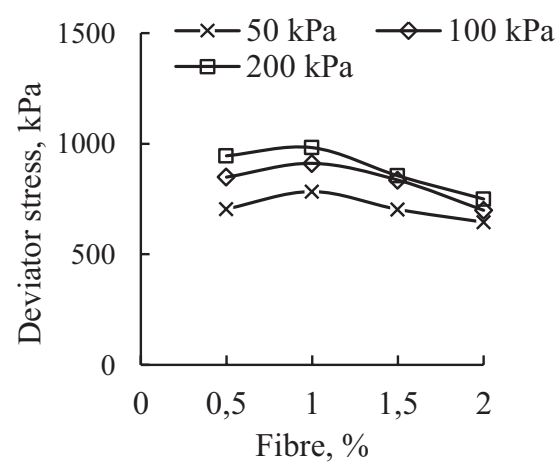

(c)

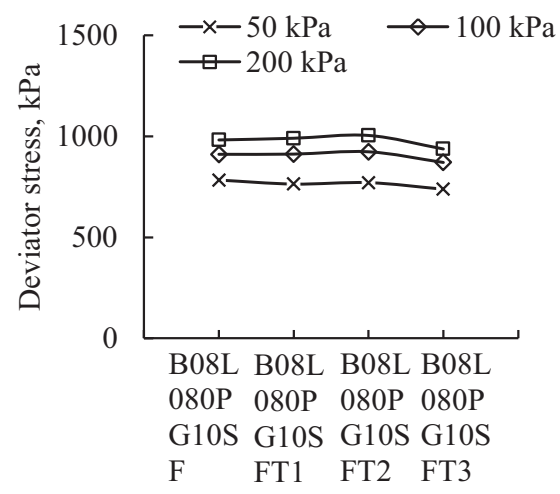

(d)

Fig. 1 Deviator stress with varying percentage of (a) lime (b) phosphogypsum (c) sisal fibre (d) treated sisal fibre
Table 4 Strength parameter of various mixes from unconsolidated undrained triaxial test

\begin{tabular}{lcc}
\hline Mixes & Cohesion, kPa & Friction angle, degrees \\
\hline B & 139.96 & 0.78 \\
B08L & 144.16 & 39.71 \\
B10L & 143.34 & 35.03 \\
B08L080PG & 421.24 & 17.42 \\
B08L100PG & 382.63 & 12.22 \\
B08L080PG10SF & 234.04 & 23.75 \\
B08L080PG10SFT1 & 215.71 & 25.81 \\
B08L080PG10SFT2 & 214.08 & 26.48 \\
B08L080PG10SFT3 & 218.90 & 23.81 \\
\hline
\end{tabular}

\subsection{Effect of chemical treatment of sisal fibers on compaction}

The untreated sisal fibres and the treated sisal fibres were successively added to B08L080PG for studying the compaction behaviour. The results of the compaction are also shown in Table 2. Study of this table reveals that the optimum moisture content of the optimum mix B08L080PG10SF decreased with the chemical treatment. For example, the optimum moisture content of the mix B08L080PG10SF was $33.00 \%$. The optimum moisture content decreased to $31.50 \%, 30.60 \%$ and 29.00 $\%$ for the mixes B08L080PG10SFT1, B08L080PG10SFT2 and $B 08 L 080 P G 10 S F T 3$ respectively. This decrease in the optimum moisture content of the optimum mix B08L080PG10SF can be attributed to the decrease in the moisture absorption tendency of the sisal fibers due to the chemical treatment. It is further evident from Table 2 that a mix B08L080PG10SFT3 absorbs less water in comparison to other mixes B08L080PG10SFT1, B08L080PG10SFT2. This is perhaps due to the fact that the third stage of treatment decreases the tendency of sisal fibers to absorb water better in comparison to second and first stage of treatment. Table 2 further reveals that the maximum dry unit weight of the optimum mix B08L080PG10SF increased with the chemical treatment. For example, maximum dry unit weight of the optimum mix B08L080PG10SF was $13.02 \mathrm{kN} /$ $\mathrm{m}^{3}$. This increased to $13.17 \mathrm{kN} / \mathrm{m}^{3}, 13.25 \mathrm{kN} / \mathrm{m}^{3}$ and $13.39 \mathrm{kN} /$ $\mathrm{m}^{3}$ for the mixes B08L080PG10SFT1, B08L080PG10SFT2 and $B 08 L 080 P G 10 S F T 3$ respectively. This increase in the dry unit weight of the optimum mix B08L080PG10SF with the addition of chemically treated fibers is attributed to the removal of surface impurities (wax, natural oils, cellulose, lignin, hemicelluloses, and lumen) from the surface of sisal fibers due to chemical treatment. It should be noted that for the mix B08L080PG10SFT3, the dry unit weight is higher in comparison to other mixes B08L080PG10SFT1, B08L080PG10SFT2 owing to the surface deposition of heavier chemicals on the sisal fibres. 


\subsection{Effect of chemical treatment of sisal fibers on unconfined compressive strength}

The untreated sisal fibres and the treated sisal fibres were successively added to B08L080PG for studying the unconfined compressive strength. The results of the unconfined compressive strength are also shown in Table 3. Study of this table reveals that for a curing period of 3 days, the unconfined compressive strength of the mix B08L080PG10SF was $515.47 \mathrm{kPa}$ which increased to $535.06 \mathrm{kPa}$ and $795.53 \mathrm{kPa}$ for the mixes B08L080PG10SFT1 and B08L080PG10SFT2 respectively. The improvement in unconfined compressive strength of the mixes B08L080PG10SFT1 and B08L080PG10SFT2 is attributed to the conversion of hydroxyl groups present in the cellulose of sisal fiber to $\mathrm{C}=\mathrm{O}$ group due to oxidation reaction which is further converted to $\mathrm{C}=\mathrm{N}$ with the coupling reaction of amino group of p-aminophenol. This chemical process leads to the removal of impurities like wax, oil and reduction in size and diameter of the loose materials deposited on the surface of the sisal fibers. Removal of impurities makes the surface cleaner and surface irregularities become clear leading to improved interaction of fibers with the bentonite-lime-phosphogypsum mix. The unconfined compressive strength for the mix B08L080PG10SFT3 decreased to $416.91 \mathrm{kPa}$. This reduction in the unconfined compressive strength for the mix B08L080PG10SFT3 is due to the delignification and the smoothening of fiber surface. Study of Table 3 further reveals that the unconfined compressive strength of the mixes B08L080PG10SFT1, B08L080PG10SFT2 and B08L080PG10SFT3 increased with the increase in curing period. This increase in unconfined compressive strength with the increase in curing period is attributed to the time dependent pozzolanic reaction between soil silica and lime leading to the formation of cementing gel which improves the adhesion in composite.

\subsection{Effect of chemical treatment of sisal fibers on deviator stress}

The untreated sisal fibres and the treated sisal fibres were successively added to B08L080PG for studying the variation of deviator stress. The results are shown in Figure 1(d) and Table 5, study of which reveals that for a curing period of 28 days, the deviator stress at failure of the mix B08L080PG10SF was $783.58 \mathrm{kPa}$ which changed to $763.59 \mathrm{kPa}, 770.59 \mathrm{kPa}$ and decreased to $738.21 \mathrm{kPa}$ for the mixes B08L080PG10SFT1, B08L080PG10SFT2 and B08L080PG10SFT3 respectively. Similar trend was observed at other confining pressures also. The increase in deviator stress at failure of the mixes B08L080PG10SFT1, B08L080PG10SFT2 and the decrease in deviator stress at failure for the mix B08L080PG10SFT3 is attributed to the removal of surface impurities and the smoothening of fiber surface respectively. The strength parameters for the mixes B08L080PG10SFT1, B08L080PG10SFT2 and B08L080PG10SFT3 are shown in Table 4.
Table 5 Summary of triaxial test results of optimum mix reinforced with treated sisal fibers

\begin{tabular}{|c|c|c|c|c|c|}
\hline \multicolumn{2}{|l|}{ Mixes } & & & & \\
\hline \multicolumn{2}{|c|}{$\begin{array}{l}\text { Confining } \\
\text { pressure, } \\
\mathrm{kPa}\end{array}$} & $\begin{array}{c}\text { B08L080 } \\
\text { PG10SF }\end{array}$ & $\begin{array}{c}\text { B08L080 } \\
\text { PG10SFT1 }\end{array}$ & $\begin{array}{c}\text { B08L080 } \\
\text { PG10SFT2 }\end{array}$ & $\begin{array}{c}\text { B08L080 } \\
\text { PG10SFT3 }\end{array}$ \\
\hline \multirow{3}{*}{$\begin{array}{l}\text { Dev. } \\
\text { Stress, } \\
\mathrm{kPa}\end{array}$} & 50 & 783.58 & 763.59 & 770.59 & 738.21 \\
\hline & 100 & 911.08 & 912.10 & 923.52 & 870.72 \\
\hline & 200 & 982.09 & 990.57 & 1004.53 & 937.51 \\
\hline
\end{tabular}

Study of Table 4 reveals that the friction angle of the optimum mix B08L080PG10SF increased with the chemical treatment up to second stage of treatment. The friction angle decreased beyond second stage of chemical treatment. For example the friction angle of the optimum mix B08L080PG10SF was $23.75^{\circ}$ which increased to $25.81^{\circ}$ and $26.48^{\circ}$ for the mixes B08L080PG10SFT1 and B08L080PG10SFT2 respectively and decreased to $23.81^{\circ}$ for the mix B08L080PG10SFT3. Table 4 further reveals that the cohesion of the optimum mix B08L080PG10SF was $234.04 \mathrm{kPa}$ which decreased to 215.71 $\mathrm{kPa}$ and $214.08 \mathrm{kPa}$ for the mixes B08L080PG10SFT1 and B08L080PG10SFT2 respectively and increased to $218.90 \mathrm{kPa}$ for the mix B08L080PG10SFT3.

\subsection{Effect of chemical treatment of sisal fibers on tensile load-diametral strain behaviour}

The untreated sisal fibres and the treated sisal fibres were successively added to B08L080PG for studying the variation of tensile load and diametral strain at failure. The specimen prepared was cured for 3, 7, 14 and 28 days. The results are shown in Table 6. Study of this table reveals that for a curing period of 3 days, the tensile load at failure of the mix B08L080PG10SF was $0.06 \mathrm{kN}$ which increased to $0.07 \mathrm{kN}$ and $0.09 \mathrm{kN}$ for the mixes B08L080PG10SFT1 and B08L080PG10SFT2 respectively. The improvement in tensile load at failure for the mixes B08L080PG10SFT1 and B08L080PG10SFT2 is attributed to the removal of impurities from the surface of the fibers leading to improved interaction with the bentonite-limephosphogypsum mix. The tensile load at failure for the mix B08L080PG10SFT3 decreased to $0.08 \mathrm{kN}$. This reduction in the tensile load at failure for the mix B08L080PG10SFT3 is perhaps attributed to the delignification and the smoothening of fiber surface. Study of Table 6 further reveals that the tensile load at failure of the mixes B08L080PG10SFT1, B08L080PG10SFT2 and B08L080PG10SFT3 increased with the increase in curing period.

This increase in tensile load at failure with the increase in curing period is due to the time dependent pozzolanic reaction between the soil silica and the lime leading to the formation of cementing gel which improves the adhesion in composite. Study of Table 6 further reveals that for a curing period of 7 days, the diametral strain at failure of the mix B08L080PG10SF 
was $6.4 \%$ which increased to $6.8 \%, 7.2 \%$ and decreased to 5.6 $\%$ for the mixes B08L080PG10SFT1, B08L080PG10SFT2 and B08L080PG10SFT3 respectively. The improvement in the diametral strain at failure for the mixes B08L080PG10SFT1 and B08L080PG10SFT2 is attributed to the fact that the improved bond of chemically treated sisal fibers with the bentonite-limephosphogypsum mix delays the propagation of crack which results in the increased diametral strain at failure of the specimen. The decrease in diametral strain at failure for the mix B08L080PG10SFT3 is due to reduction in the bond of chemically treated sisal fiber with the bentonite-lime-phosphogypsum mix due to the smoothening of the sisal fiber surface.

Table 6 Tensile load at failure for the optimum mix reinforced with treated sisal fibers and cured for $3,7,14$ and 28 days

\begin{tabular}{|c|c|c|c|c|c|}
\hline \multicolumn{2}{|c|}{ Mixes } & \multirow{2}{*}{$\begin{array}{l}\text { B08L080 } \\
\text { PG10SF }\end{array}$} & \multirow{2}{*}{$\begin{array}{c}\text { B08L080 } \\
\text { PG10SFT1 }\end{array}$} & \multirow{2}{*}{$\begin{array}{c}\text { B08L080 } \\
\text { PG10SFT2 }\end{array}$} & \multirow{2}{*}{$\begin{array}{c}\text { B08L080 } \\
\text { PG10SFT3 }\end{array}$} \\
\hline & ing period, & & & & \\
\hline \multirow{2}{*}{3} & $\begin{array}{l}\text { Tensile } \\
\text { Load, kN }\end{array}$ & 0.06 & 0.07 & 0.09 & 0.08 \\
\hline & $\begin{array}{l}\text { Diametral } \\
\text { strain, } \%\end{array}$ & 4 & 5.2 & 5.2 & 5.2 \\
\hline \multirow{2}{*}{7} & $\begin{array}{l}\text { Tensile } \\
\text { Load, kN }\end{array}$ & 0.07 & 0.13 & 0.14 & 0.14 \\
\hline & $\begin{array}{l}\text { Diametral } \\
\text { strain, } \%\end{array}$ & 6.4 & 6.8 & 7.2 & 5.6 \\
\hline \multirow{2}{*}{14} & $\begin{array}{l}\text { Tensile } \\
\text { Load, kN }\end{array}$ & 0.12 & 0.14 & 0.17 & 0.14 \\
\hline & $\begin{array}{l}\text { Diametral } \\
\text { strain, } \%\end{array}$ & 6.8 & 7.2 & 8.0 & 8.0 \\
\hline \multirow{2}{*}{28} & $\begin{array}{l}\text { Tensile } \\
\text { Load, kN }\end{array}$ & 0.19 & 0.21 & 0.22 & 0.18 \\
\hline & $\begin{array}{l}\text { Diametral } \\
\text { strain, \% }\end{array}$ & 7.2 & 7.6 & 8.4 & 6.0 \\
\hline
\end{tabular}

\subsubsection{Toughness Characteristics}

To better understand the toughening characteristics of the untreated and the treated sisal fibers in the post peak region, the tensile load $(P)$ on the load axis and the deformation $(d)$ on deformation axis were normalized with the peak tensile load $\left(P_{p}\right)$ and the deformation at peak load $\left(d_{p}\right)$ as shown in Figure 2. The variation of normalized load-deformation curve for the mixes B08L080PG10SF, B08L080PG10SFT1, B08L080PG10SFT2 and B08L080PG10SFT3 cured for 3, 7, 14 and 28 are shown in Figures 2 (a) to (d). An examination of Figures 2 (a) to (d) reveals the improved post peak behaviour for the mixes B08L080PG10SFT1, B08L080PG10SFT2 whereas no such improvement is visible for the mix B08L080PG10SFT3 as evident from Figure 2(d). It is further observed from Figures 2 (a) to (d) that addition of the treated sisal fiber to the mix B08L080PG10SF changes the behaviour from ductile to more ductile for the mixes B08L080PG10SFT1 and B08L080PG10SFT2 whereas reverse change in the behaviour is observed for the mix B08L080PG10SFT3.

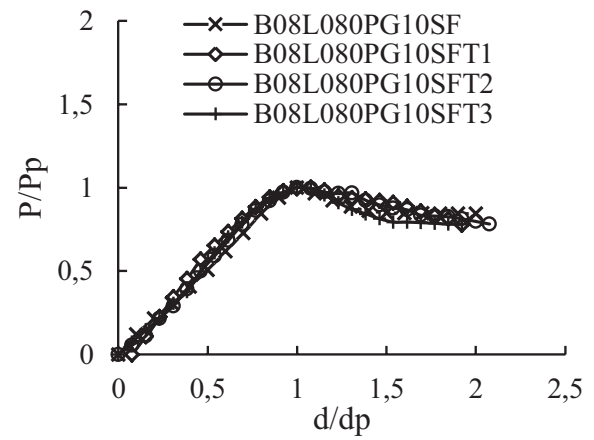

(a)

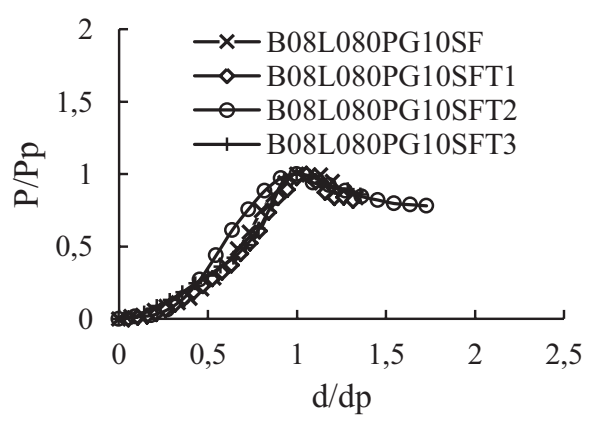

(b)

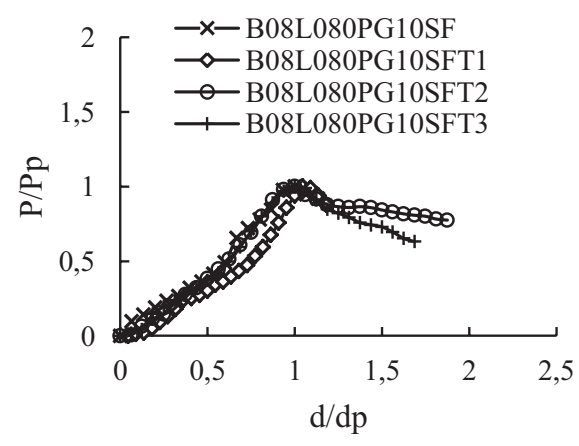

(c)

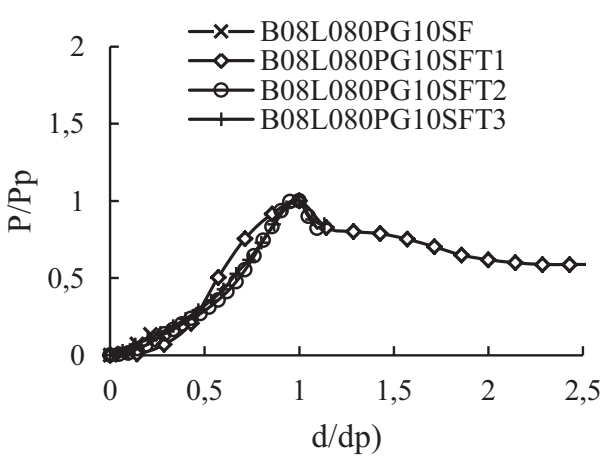

(d)

Fig. 2 Normalized tensile load-diametral deformation behaviour of various mix at (a) 3 days (b) 7 days (c) 14 days (d) 28 days 


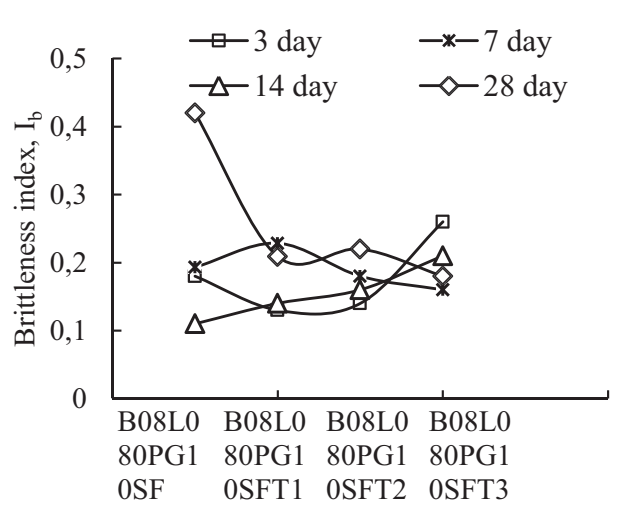

Fig. 3 Variations of brittleness index of various mixes with curing period

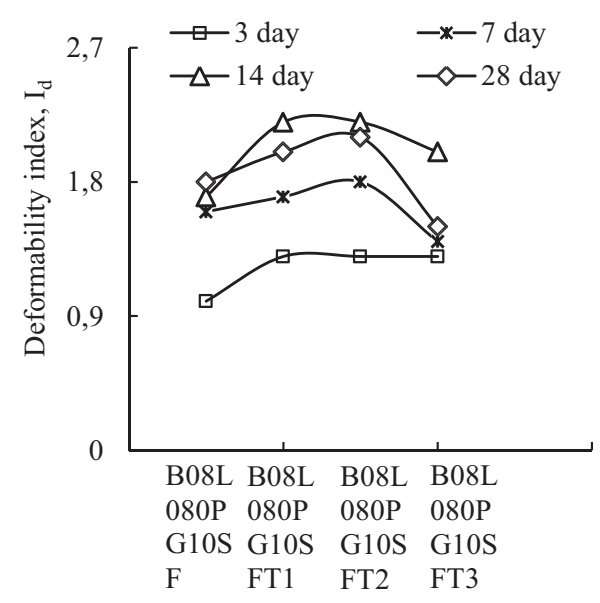

Fig. 4 Variations of deformability index of various mixes with curing period

To verify this, a dimensionless parameter called brittleness index (ratio of peak strength to ultimate strength, $I_{b}$ ) [30] and deformability index (ratio of diametral strain at failure of the mix B08L080PG10SFT1 or B08L080PG10SFT2 or $B 08 L 080 P G 10 S F T 3$ to the diametral strain at failure of the mix B08L080PG10SF,$I_{d}$ ) [31] were calculated using Eqs. (1) and (2) and the results are shown in Figures 3 and 4 respectively. The indices present the ductility behaviour of the chemically treated sisal fibres added to bentonite-lime-phosphogypsum with the increase in the curing period.

$$
I_{b}=\left(\frac{q_{f}}{q_{u l t}}\right)-1
$$

$$
I_{d}=\frac{\Delta_{\text {B08L080PG10SFT1 or B08L080PG10SFT2 or B08L080PG10SFT3 }}}{\Delta_{\text {B08L080PG10SF }}} 2
$$

In Eq. (1), $\mathrm{q}_{\mathrm{f}}$ is the peak tensile strength and $\mathrm{q}_{\text {ult }}$ is the ultimate tensile strength of the mixes whereas in Eq. (2), is the diametral strain at failure of the mixes B08L080PG10SFT1, B08L080PG10SFT2 and B08L080PG10SFT3 and is the diametral strain at failure of the mix B08L080PG10SF.
Study of Figure 3 reveals that the brittleness index at a curing period of 3 days was 0.18 for the mix B08L080PG10SF, which changed to 0.13 and 0.14 for the mixes B08L080PG10SFT1 and $B 08 L 080 P G 10 S F T 2$ respectively. The brittleness index increased to 0.26 for the mix B08L080PG10SFT3. The increase in the brittleness index indicates brittle behaviour whereas decrease in the brittleness index indicates ductile behaviour. The chemical treatment was effective in reducing the brittleness of the bentonitelime-phosphogypsum-untreated sisal fibre composite. Study of Figure 4 reveals that the deformability index at 7 days of curing for the mix B08L080PG10SF was 1.6, which increased to 1.7 and 1.8 for the mixes B08L080PG10SFT1 and B08L080PG10SFT2 respectively. The deformability index decreased to 1.4 for the mix B08L080PG10SFT3 at the same curing period. This trend was consistent with all curing periods as evident from Figure 4. It can be further observed from Figure 4 that the deformability index for the mixes increased with the increase in curing period. The increase in the deformability index indicates ductile behaviour whereas the decrease in the deformability index indicates brittle behaviour. Further from the Figure 4, it can be observed that the change in the behaviour from brittle to ductile is higher for shorter curing periods whereas the rate of increase in the deformability index is lesser for longer curing period. This may be due to the pozzolanic reaction.

\section{SEM and EDAX Studies}

Scanning electron micrographs of the mixes bentonite, B08L, B08L080PG, the untreated sisal fiber and the treated sisal fibres are shown in Figure 5(a) to (g).

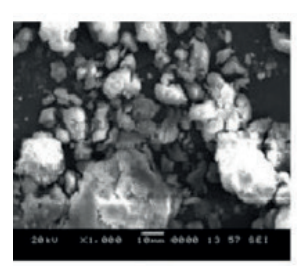

(a)

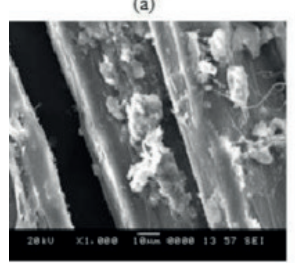

(d)

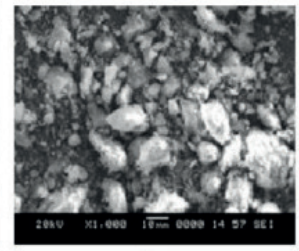

(b)

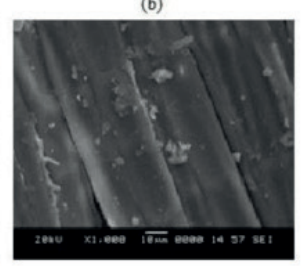

(e)

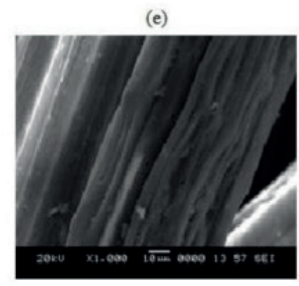

(g)

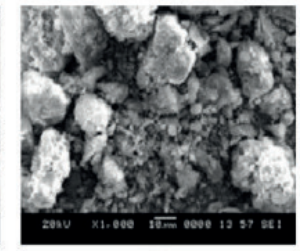

(c)

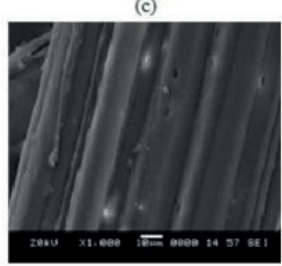

(f)
Fig. 5 Scanning Electron Micrograph of (a) bentonite (b) B08L (c) $B 08 L 080 P G$ (d) sisal fibre (e) SFT1 (f) SFT2 (g) SFT3 
A summary of $E D A X$ analysis is presented in Table 7 . Study of Figure 5(a) reveals the particles of bentonite whereas Figure 5(b) shows the formation of compact matrix (cementing gel) in bentonite due to the time dependent pozzolanic reaction between the soil silica and the lime leading to an increase in the compressive strength as discussed in Section 4.1. This is evidently substantiated by the increase in the $\mathrm{Ca}$ :Si ratio of bentonite with the addition of lime proving the $C-S-H$ formations. An observation of the Ca:Si ratios of B08L and B10L parallels the decrease in the effect of lime on the strength behaviour of the mix. Study of Figure 5(c) reveals the possible formation of ettringite due to sulphates and is responsible for the reduction in the unconfined compressive strength of B08L080PG mix beyond a curing period of 14 days. The EDAX provides a deep understanding of the morphological changes with the further addition of phosphogypsum. This leads to an increase in the Aluminium content and reduces the strength as shown in the decreasing Si:Al ratios in Table 7 . Figures 5(d) to (g) show a node-like structure on the surface of sisal fiber. This node-like structure gets reduced in the first stage and the second stage of chemical treatment resulting in the removal of materials such as lignin, oil and waxes and improving the surface characteristics of sisal fiber which in turn results in improving the bonding of treated sisal fibers with the bentonite-lime-phosphogypsum mix.

Table 7 Summary of $E D A X$ analysis

\begin{tabular}{lccc}
\hline MIXES & Curing period, days & $\mathbf{C a} / \mathbf{S i}$ & Si/Al \\
\hline Bentonite & - & 0.0002 & 2.2696 \\
B08L & 7 & 0.1727 & 2.1556 \\
B10L & 28 & 0.2577 & 1.8765 \\
& 28 & 0.2198 & 1.9766 \\
B08L080PG & 7 & 0.2351 & 2.0000 \\
& 14 & 0.4000 & 1.9557 \\
B08L100PG & 28 & 0.2706 & 1.8300 \\
\hline
\end{tabular}

\section{Conclusions}

An experimental study is carried out to investigate the effect of treated sisal fiber on the engineering properties of bentonitelime-phosphogypsum mix using a multi variable approach. On the basis of the results of the experimental investigation and the discussions made in the earlier sections, the following conclusions can be drawn.

1. The dry unit weight of the optimum mix increased and the optimum moisture content decreased with the chemical treatment. The high moisture sorption of the untreated sisal fibres was thus decreased with the surface modification of fibres by the chemicals.

2. The unconfined compressive strength, the deviator stress, the tensile load and the diametral strain at failure of the optimum mix increased up to the second stage of chemical treatment. Beyond the second stage of treatment, the unconfined compressive strength, deviator stress and the tensile load decreased. Thus, the successive surface modifications with the use of sodium periodate and p-aminophenol produced maximum change in the engineering properties. This also makes way for further extensive research in the field of geosynthetics.

3. The unconfined compressive strength, the tensile load and the diametral strain at failure increased with the increase in the curing period for all the mixes studied.

4. The post peak behaviour of the untreated sisal fibres mixed with bentonite-lime-phosphogypsum increased/ improved with the chemical treatment. The brittleness index and the deformability index reveals the effect of ductility brought in with the chemical modification.

\section{Notation}

$B$

$d$

$d_{p}$

$I_{d}$

EDAX

$I_{b}$

$L$

$M D D$

$O M C$

$P$

$P_{p}$

$P G$

$q_{u}$

SEM

SF
Bentonite

Deformation

Deformation at peak load

Deformability index

Energy Dispersive X-ray Analysis

Brittleness index

Lime

Maximum dry unit weight, $\mathrm{kN} / \mathrm{m}^{3}$

Optimum moisture content, $\%$

Tensile load, $\mathrm{kN}$

Peak tensile load, $\mathrm{kN}$

Phosphogypsum

Unconfined Compressive Strength, $\mathrm{kN} / \mathrm{m}^{2}$

Scanning Electron Micrograph

Sisal Fiber

\section{References}

[1] Kumar, S., Dutta, R. K., Mohanty, B. "Potential of bentonite-lime-mix modified with phosphogypsum and reinforced with sisal fibres." Periodica Polytechnica Civil Engineering. 59(2), pp. 143-154. 2015. https:// doi.org/10.3311/PPci.7733

[2] Oladele, I. O., Daramola, O. O., Fasooto, S. "Effect of chemical treatment on the mechanical properties of sisal fiber reinforced polyester composites." Leonardo Electronic Journal of Practicesand Technologies. 24, pp. 1-12. 2014.

[3] Li, Z., Zhou, X., Pei, C. "Effect of sisal fiber surface treatment on properties of sisal fiber reinforced polylactide composites." International Journal of Polymer Science. 2011, Article ID 803428. 2011. https://doi. org/10.1155/2011/803428

[4] Joseph, K., Thomas, S., Pavithran, C. "Effect of chemical treatment on the tensile properties of short sisal fiber-reinforced polyethylene composites." Polymer. 37(23), pp. 5139-5149. 1996. https://doi. org/10.1016/0032-3861(96)00144-9

[5] Bisanda, E. T. N. "The effects of alkali treatment on the adhesion characteristics of sisal fibers." Applied Composite Materials. 7(5), pp. 331-339. 2000. https://doi.org/10.1023/A:1026586023129 
[6] Mwaikambo, L. Y., Ansell, M. P. "The effect of chemical treatment on the properties of hemp, sisal, jute and kapok fibers for composites reinforcement." In: $2^{\text {nd }}$ International Wood and Natural Fiber Composites Symposium, Kassel, Germany, June 28-29, 1999, pp. 12-1-12-16.

[7] Li, X., Tabil, L. G., Panigrahi, S. "Chemical treatments of natural fiber for use in natural fiber-reinforced composites: A review." Journal of Polymers and the Environment. 15(1), pp. 25-33. 2007. https://doi.org/ 10.1007/s10924-006-0042-3

[8] Oladele, I. O., Omotoyinbo, J. A., Adewara, J. O. T. "Investigating the effect of chemical treatment on the constituents and tensile properties of sisal fiber." Journals of Minerals \& Materials Characterization \& Engineering, 9(6), 569-582. 2010. https://doi.org/10.4236/jmmce.2010.96041

[9] Rong, M. Z., Zhang, M. Q., Liu, Y., Yang, G. C., Zeng, H. M. "The effect of fiber treatment on the mechanical properties of unidirectional sisalreinforced epoxy composites." Composites Science and Technology. 61, pp. 1437-1447. 2001. https://doi.org/10.1016/S0266-3538(01)00046-X

[10] Kaushik, V. K., Kumar, A., Kalia, S. "Effect of mercerization and benzoyl peroxide treatment on morphology, thermal stability and crystallinity of sisal fibers." International Journal of Textile Science. 1(6), pp. 101-105. 2012. https://doi.org/10.5923/j.textile.20120106.07

[11] Barra, B., Paulo, B., Junior, C. A., Junior, H. S., Ghavami, K. "Effects of methane cold plasma in sisal fibers." Key Engineering Materials. 517, pp. 458-468. 2012.

[12] Hejazi, S. M., Sheikhzadeh, M., Abtahi, S. M., Zadhoush, A. “A simple review of soil reinforcement by using natural and synthetic fibers." Construction and Building Materials. 30, pp. 100-116. 2012.

[13] Amico, S. C., Mochnacz, S., Sydenstricker, T. H. D. "Tratamento melhora propriedades de fibras de sisal para uso em compósitos - Revista Plástico Industrial.” São Paul, Editora Aranda. 2004.

[14] Jang, B. Z. "Interfaces and Interphases in Composites." Advanced Polymer Composites. ASM International, Materials Park, OH. 1994.

[15] Kozlowski, R., Mieleniak, B. "New trends in the utilization of byproducts of fiber crops residue in pulp and paper industry, building engineering, automotive industry and interior furnishing." In: Proceedings from the Third International Symposium on Natural Polymers and Composites, Sao Paulo, pp. 504-510. 2000.

[16] Ray, D., Sarkar, B. K., Rana, A. K., Bose, N. R. "The mechanical properties of vinylester resin matrix composites reinforced with alkali-treated jute fibers." Composites Part A: Applied Science and Manufacturing. 32(1), pp. 119-127. 2001. http://dx.doi.org/10.1016/S1359835X(00)00101-9

[17] Sydenstricker, T. H. D., Mochanaz, S., Amico, S. C. "Pull-out and other evaluations in sisal-reinforced polyester biocomposites." Polymer Testing. 22(4), pp. 375-380. 2003. http://dx.doi.org/10.1016/S01429418(02)00116-2

[18] Sreekumar, P. A., Thomas, S. P., Saiter, J. M., Kuruvilla, J., Unnikrishnan, G., Sabu, T. "Effect of fiber surface modification on the mechanical and water absorption characteristics of sisal/polyester composites fabricated by resin transfer molding." Composites Part A: Applied Science and Manufacturing. 40(11), pp. 1777-1784. 2009. https://doi.org/10.1016/j. compositesa.2009.08.013

[19] Priya, V. K., Girish, M. S. "Effect of sisal fibers on lime treated black cotton soil." ICTT Civil Engineering Papers, Institutional Repository of College of Engineering Trivandrum, pp. 1-6. 2010.

[20] Manjunath, K. R., Venugopal, G., Rudresh, A. N. "Effect of random inclusion of sisal fiber on strength behavior of black cotton soil." International Journal of Engineering Research \& Technology (IJERT). 2(7), 2227-2232. 2013.
[21] Kumar, S., Dutta, R. K. "Unconfined compressive strength of bentonitelime-phosphogypsum mixture reinforced with sisal fibers." Jordan Journal of Civil Engineering. 8(3), pp. 239-250. 2014.

[22] IS: 2809. "Glossary of terms and symbols relating to soil engineering. Indian Standard methods of test for soils.” Bureau of Indian Standards, New Delhi, 1-9. 1972.

[23] IS: 2720, Part III-Sec I. "Determination of specific gravity, Fine grained soils." Indian Standard methods of test for soils. Bureau of Indian Standards, New Delhi, 1-9. 1980.

[24] IS: 2720, Part VII. "Laboratory determination of water content-dry density relation using light compaction. Indian Standard methods of test for soils.” Bureau of Indian Standards, New Delhi, 1-9. 1980.

[25] S: 2720, Part X. "Determination of unconfined compressive strength. Indian Standard methods of test for soils.” Bureau of Indian Standards, New Delhi, 1-4. 1991.

[26] IS: 2720, Part XI. "Determination of the shearstrength parameters of a specimen tested in unconsolidated undrained triaxial compression without the measurement of pore water pressure. Indian Standard methods of test for soils." Bureau of Indian Standards, New Delhi, 1-6. 1993.

[27] IS: 10082. "Method of test for determination of tensile strength by indirect tests on rock specimens." Indian Standard. Bureau of Indian Standards, New Delhi, 1-12. 1981.

[28] Wild, S., Kinuthia, J. M., Robinson, R. B., Humphreys, I. "Effects of ground granulated blast furnace slag (GGBS) on the strength and swelling properties of lime-stabilized kaolinite in the presence of sulphates." Clay Minerals. 31, pp. 423-433. 1996.

[29] Krishna, S., Sayida, M. K. "Behaviour of black cotton soil reinforced with sisal fiber." In: 10th National Conference onTechnological Trends, College of Engineering Trivandrum, India. 2009.

[30] Consoli, N. C., Prietto, P. D. M., Ulbrich, L. A. "Influence of fiber and cement addition on behavior of sandy soil." Journal of Geotechnical and Geoenvironmental Engineering. 124(12), pp. 1211-1214. 1998. https://doi.org/10.1061/(ASCE)1090-0241(1998)124:12(1211)\#sthash. EL6zDNN2.dpuf

[31] Park, S.-S. "Unconfined compressive strength and ductility of fiber-reinforced cemented sand." Construction and Building Materials. 25(2), pp. 1134-1138. 2011. http://dx.doi.org/10.1016/j.conbuildmat.2010.07.017 